\title{
Replication fork instability and the consequences of fork collisions from rereplication
}

\author{
Jessica L. Alexander and Terry L. Orr-Weaver \\ Whitehead Institute, Department of Biology, Massachusetts Institute of Technology, Cambridge, Massachusetts 02142, USA
}

Replication forks encounter obstacles that must be repaired or bypassed to complete chromosome duplication before cell division. Proteomic analysis of replication forks suggests that the checkpoint and repair machinery travels with unperturbed forks, implying that they are poised to respond to stalling and collapse. However, impaired fork progression still generates aberrations, including repeat copy number instability and chromosome rearrangements. Deregulated origin firing also causes fork instability if a newer fork collides with an older one, generating double-strand breaks (DSBs) and partially rereplicated DNA. Current evidence suggests that multiple mechanisms are used to repair rereplication damage, yet these can have deleterious consequences for genome integrity.

Complete and accurate duplication of DNA at each S phase is required to maintain genome integrity in dividing cells. This is accomplished by exquisite control of the DNA replication program at the level of both origin firing and replication fork progression. Genome stability requires that fork elongation is complete across every chromosome. However, not all genomic positions are replicated equally. DNA damage as well as intrinsic sequence and structural properties of the chromosome can slow or prevent passage of the replication fork. Failure to alleviate these blockades can lead to incomplete genome duplication, resulting in chromosome breakage, fusions, and rearrangements.

Many of the components that constitute the replication fork are well defined, and recent proteomics analyses have cataloged fork components during normal elongation as well as under stress conditions. Increasing evidence suggests that replication forks recruit repair components even during unstressed replication, revealing that this sys-

[Keywords: gene amplification; double-strand break repair; nonhomologous end-joining; homologous recombination; break-induced replication]

Corresponding author: weaver@wi.mit.edu

Article is online at http://www.genesdev.org/cgi/doi/10.1101/gad.288142. 116. Freely available online through the Genes \& Development Open Access option. tem is well poised to respond to fork impediments. Despite this, fork collapse and the resulting DNA damage are observed under a variety of conditions that block fork elongation. Although significant advances have been made, the mechanisms that maintain fork stability and repair damaged forks continue to be explored.

Regulated origin firing also is essential for genome integrity, and refiring of a single origin within the same $S$ phase generates double-strand breaks (DSBs) and activates the DNA damage checkpoint. Rereplication forks are slow moving, and even multiple refired origins are not able to replicate the chromosome fully (Nguyen et al. 2001). Recent evidence reveals that DNA damage generated during rereplication is the result of instability at the replication forks, consistent with their slow progression. Continued elongation is dependent on the DNA damage checkpoint and DSB repair components. These results support the fork collision model of DSB generation during rereplication, by which adjacent forks experience head-totail collisions and subsequent fork collapse (Davidson et al. 2006). How these rereplication-induced DSBs are repaired is still under investigation, and current evidence varies between experimental systems. There are increasing indications that the actual repair events can exacerbate the damage depending on the location of rereplication and the mechanism of repair. These results suggest that not only fork instability but also repair of collapsed forks contribute to genome instability.

Assembly and structure of the eukaryotic replication fork In $\mathrm{G} 1$ of the cell cycle, origins of replication are bound by the prereplication complex (pre-RC). This complex includes the origin recognition complex $(\mathrm{ORC}$; which directly binds to the DNA) as well as Cdc6, Cdt1, and the Mcm2-7 complex (Tanaka and Araki 2013). Cdt1 recruits Mcm2-7 to ORC and Cde6-bound origins, and in vitro studies show that both Cdc 6 and Cdt1 quickly disassociate once Mcm2-7 is stably loaded (Ticau et al. 2015).

(C) 2016 Alexander and Orr-Weaver This article, published in Genes \& Development, is available under a Creative Commons License (Attribution 4.0 International), as described at http://creativecommons.org/licenses/ by $/ 4.0 /$. 
The Mcm2-7 complex is sequentially loaded as a head-tohead double hexamer onto the dsDNA origin to facilitate bidirectional fork movement (Tanaka and Araki 2013; Ticau et al. 2015). Once assembled, the origin is said to be licensed.

DDK and CDK phosphorylation events lead to the recruitment of Cdc45 and the GINS complex (Sld5, Pif1, Pif2, and Pif3), which, together with Mcm2-7, comprise the CMG (Cdc45, Mcm2-7 complex, and GINS complex) helicase that unwinds the dsDNA for replication (Tanaka and Araki 2013). Assembly of the helicase also is dependent on the regulatory components Sld2, Sld3, Sld7, and Dbp11 in budding yeast and TopBP1/Mus101, RecQL4/ RecQ4, and Treslin/Ticrr in higher eukaryotes; together with the CMG and DNA polymerase $\varepsilon(\mathrm{Pol} \varepsilon)$, these components comprise the preinitiation complex (pre-IC) (Tanaka and Araki 2013).

The elongation phase of DNA replication consists of replication fork progression and DNA synthesis at the fork. Assembly of the pre-IC and origin melting are accompanied by activation of the CMG helicase and polymerase recruitment. This requires that the MCM2-7 complex transitions from encircling dsDNA as part of the pre-RC to ssDNA as part of the replication fork. The CMG helicase translocates along the leading strand, supporting a model in which the DNA is unwound by steric exclusion from the Mcm2-7 central channel (Fig. 1; Fu et al. 2011). Replication of the leading and lagging strands is coordinated with helicase unwinding in a large protein complex called the replisome; together, the replicating DNA and replisome constitute the replication fork (Fig.
1; Johnson and O'Donnell 2005). Fork progression also must be coordinated with disassembly of nucleosomes ahead of the fork and re-establishment of nucleosomes and the chromatin state on newly synthesized DNA. Nucleosome deposition is coordinated with fork elongation by interactions between histone chaperones and fork components (Alabert and Groth 2012). In addition, chromatin marks must be re-established on newly synthesized histones (Alabert and Groth 2012).

In the past 5 years, several methodologies have been developed for the capture of active replication forks and assessment of associated protein components (Kliszczak et al. 2011; Sirbu et al. 2011, 2013; Lopez-Contreras et al. 2013; Alabert et al. 2014). Isolation of proteins bound to nascent DNA (iPOND) and DNA-mediated chromatin pull-down (DM-ChP) use the thymidine analog EdU and click chemistry to pull down DNA fragments into which EdU is incorporated (Kliszczak et al. 2011; Sirbu et al. 2011). Short pulses of EdU followed by fixation allow selective pull-down of components at active replication forks, although newly synthesized DNA behind the replication fork also may be recovered (Sirbu et al. 2011, 2013; Lopez-Contreras et al. 2013). An EdU pulse followed by a thymidine chase results in pull-down of mature chromatin marks and the responsible remodelers (Sirbu et al. 2011; Lopez-Contreras et al. 2013). A similar approach, termed nascent chromatin capture (NCC), incorporates biotin-dUTP rather than EdU into replicating DNA (Alabert et al. 2014). Combining these techniques with mass spectrometry methods has allowed for proteomics analysis of active, stalled, and collapsed replication forks as

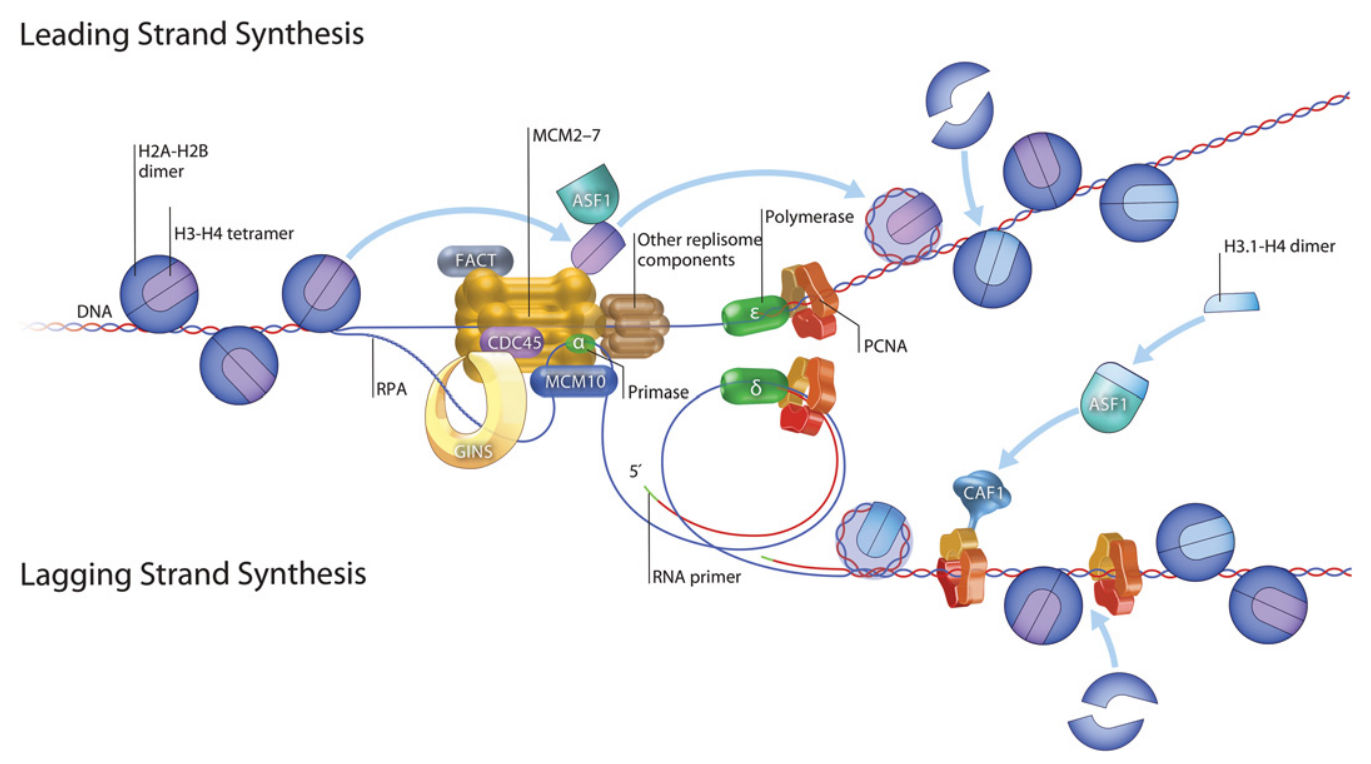

Figure 1. Summary of the eukaryotic DNA replication fork. Cdc45, the Mcm2-7 complex, and the GINS complex comprise the CMG helicase that unwinds the dsDNA. Leading strand synthesis is shown at the top and is accomplished by Pol $\varepsilon$. Lagging strand synthesis is depicted below. Pol a primase synthesizes 8- to 15-nucleotide-long RNA primers along the lagging strand. Synthesis of the lagging strand is performed by Pol $\delta$. PCNA binds to Pol $\delta$ and Pol $\varepsilon$ to enhance processivity. The nucleosome remodelers FACT and ASF1 bind to Mcm2-7 to coordinate removal of nucleosomes with the oncoming replication fork. ASF1 also cooperates with CAF-1 to deposit new H3-H4 tetramers behind the elongating fork. (Illustration by Steven Lee, http://www.graphiko.com. Adapted by permission from Macmillan Publishers Ltd: Nature Reviews Molecular Cell Biology [Alabert and Groth 2012] (1) 2012.) 
well as chromatin maturation (Kliszczak et al. 2011; Lopez-Contreras et al. 2013; Sirbu et al. 2013; Alabert et al. 2014).

These approaches have produced insights into repair at the replication fork. iPOND analysis of forks in the presence of hydroxyurea (HU) detected known checkpoint proteins at stalled forks (Sirbu et al. 2011, 2013). When fork collapse is induced by long HU exposure or ATR knockdown, high levels of DSB repair components are pulled down (Sirbu et al. 2011, 2013). An interesting finding emerging from fork component characterization is that several checkpoint and repair proteins are detected at replication forks in the absence of damaging conditions (Sirbu et al. 2011, 2013; Alabert et al. 2014). These results raise the interesting possibility that forks are poised to deal with stalling throughout $S$ phase. This property may be essential as forks proceed through difficult to replicate regions of the genome and for timely response to DNA damage and exogenous fork stress. However, it cannot be excluded that the repair proteins detected in these studies localize to spontaneously damaged forks in the population. This latter explanation is made less likely by the expectation that the proportional contribution of such forks would to be low.

\section{Impediments to replication fork progression}

Once replication forks are established, there are numerous challenges that the forks may face before replication is completed. DNA damage such as interstrand cross-links cannot be unwound, and protein-DNA cross-links form barriers to the CMG helicase (Fu et al. 2011); these lesions require specialized pathways for repair and/or bypass (Duxin et al. 2014; Zhang et al. 2015). Other forms of damage, such as UV- and methyl methanesulfonate (MMS)-induced damage, block replication and cause uncoupling of the CMG helicase and polymerases (Byun et al. 2005), similar to chemical inhibition of polymerase activity by aphidicolin. Additionally, the dNTP and histone supply must be coordinated with fork elongation for proper Sphase progression and fork stability (Nelson et al. 2002; Mantiero et al. 2011; Poli et al. 2012; Mejlvang et al. 2014). It has been shown that disruption of the origin activation timing program leads to dNTP depletion, causing slowed fork elongation, fork stalling, and checkpoint activation (Mantiero et al. 2011; Poli et al. 2012). These studies highlight the importance of the replication program in coordinating fork elongation with a steady supply of raw materials for DNA synthesis.

It has been observed widely that specific regions of the genome are particularly prone to damage in the presence of replication stress, indicating that endogenous characteristics of the DNA sequence and/or chromatin structure can be problematic for fork progression; these regions are termed fragile sites. Fragile sites are defined formally as positions of constriction or breakage on metaphase chromosomes after exposure to replication stress (Ozeri-Galai et al. 2012) and can be subdivided into rare fragile sites (RFCs) and common fragile sites (CFSs). CFSs are posi- tions that exhibit fragility across most individuals of a population, and the frequency of breakage is referred to as CFS expression (Debatisse et al. 2012). It is thought that CFSs are inherently difficult to replicate, as CFS expression is seen when the ATR checkpoint is inhibited in the absence of exogenous stress (Ozeri-Galai et al. 2012). Similarly, replication slow zones (RSZs) in yeast are prone to fork stalling and DNA breaks in the absence of the ATR homolog Mec1 (Ozeri-Galai et al. 2012). However, increased fork stalling is not observed across all metazoan CFSs (Debatisse et al. 2012; Ozeri-Galai et al. 2012). Instead, there is a collection of characteristics that are common but not universal among expressed CFSs: slow fork progression and/or frequent fork stalling, actively transcribed genes during replication, late replication timing, and lack of replication origins (Debatisse et al. 2012; Ozeri-Galai et al. 2012).

DNA sequence can impact CFS expression in several ways. Various forms of repetitive DNA can form DNA secondary structures in the ssDNA formed on the lagging strand during replication and block the replication fork (Mirkin and Mirkin 2007). Slow-replicating CFSs contain AT dinucleotide repeats (Ozeri-Galai et al. 2012), which exhibit hyperflexibility and can form secondary structures (Mirkin and Mirkin 2007). Replication forks frequently stall at these AT repeats and lead to DNA breaks in the absence of replication stress, and stalling is enhanced in the presence of aphidicolin (Ozeri-Galai et al. 2012). Secondary structures formed by trinucleotide repeats cause fork pausing and reversal and frequently correspond to break formation (Follonier et al. 2013; Liu et al. 2013; Gerhardt et al. 2014). One extensively studied example is G quadruplexes (G4s), highly stable secondary structures that form at stretches of G-rich DNA. G4s have been implicated in regulating gene expression (Maizels and Gray 2013) and origin selection (Besnard et al. 2012; Hoshina et al. 2013; Valton et al. 2014) in metazoan cells yet paradoxically pose a threat to genome stability by blocking replication forks. Replication across G4s requires specialized helicases such as FANCJ (London et al. 2008; Wu et al. 2008; Schwab et al. 2013) and Pif1 (Sanders 2010; Paeschke et al. 2011).

Fragile sites are prevalent in Drosophila endocycling tissues. The endocycle is a cell cycle variant composed of consecutive $S$ and $G$ phases in the absence of mitosis, resulting in increased cell ploidy (Smith and Orr-Weaver 1991). Replication of heterochromatin is actively repressed during the endocycle. This reduces the copy number of heterochromatic sequences compared with the overall cell ploidy and is known as underreplication. Certain euchromatic regions also are underreplicated during the endocycle in a tissue-specific manner (Nordman et al. 2011; Sher et al. 2012; Yarosh and Spradling 2014). In Drosophila, DNA damage and generation of DSBs lead to phosphorylation of the histone variant $\mathrm{H} 2 \mathrm{Av}$ (Madigan et al. 2002), similar to H2AX in mammals (Rogakou et al. 1998); the phosphorylated histone is referred to as $\gamma \mathrm{H} 2 \mathrm{Av} . \gamma \mathrm{H} 2 \mathrm{Av}$ is present throughout underreplicated sites of salivary gland chromosomes, showing that there is persistent DSB formation at these sites (Andreyeva 
et al. 2008; Nordman et al. 2014). Additionally, the observation that $\gamma \mathrm{H} 2 \mathrm{Av}$ is present across entire underreplicated domains rather than at the borders indicates that replication forks are not completely blocked but destabilized as they progress through these regions (Nordman et al. 2014).

Underreplication is dependent on the intriguing suppressor of underreplication (SUUR) protein, and SuUR mutants both restore copy number and alleviate DNA damage (Belyaeva et al. 1998; Andreyeva et al. 2008; Nordman et al. 2011, 2014; Sher et al. 2012). The SUUR protein has been demonstrated to be a dosage-sensitive inhibitor of fork progression that tracks with replication forks in particular genomic regions (Nordman et al. 2014). It appears that SUUR acts by destabilizing replication forks, but the underlying mechanism as well as the control of positional specificity await elucidation. Although fulllength SUUR has no known human homologs, the N terminus is homologous to the SWI/SNF family ATPase/ helicase domain (Makunin et al. 2002). However, residues essential for ATP binding and hydrolysis are not conserved, and thus SUUR may act as a decoy. It is an intriguing possibility that catalytically dead SWI/SNF homologs could function in other organisms to regulate fork progression during development.

\section{Detection of fork stalling and repair of collapsed replication forks}

Obstructions to replication fork progression cause fork stalling and increase the likelihood of fork collapse and breakage. Although stalled forks can resume replication once the barrier or fork stress is alleviated, replication fork stalling can lead to uncoupling of the CMG helicase and DNA polymerases (Byun et al. 2005). Uncoupling results in extended RPA binding to exposed ssDNA that initiates a checkpoint response (Zou and Elledge 2003; Byun et al. 2005). ATR binds to the RPA-coated ssDNA via its binding partner, ATRIP (Zou and Elledge 2003). TopBP1 (Mus101 in Drosophila and Dbp11 in yeast) signaling from stalled forks recruits the Rad9-Rad1-Hus1 (9-1-1) complex (Yan and Michael 2009), and interaction with Rad9 facilitates activation of ATR by TopBP1 (Kumagai et al. 2006; Delacroix et al. 2007; Lee et al. 2007). iPOND and NCC experiments raised the possibility that TopBP1 travels with elongating forks in the absence of fork stress (Sirbu et al. 2013; Alabert et al. 2014), poising it as a first responder to replication stress. ATR activation leads to phosphorylation of several substrates in the DNA damage response, including Chk1 (Liu et al. 2000). Activated Chk1 then prevents initiation of origins near stressed replication forks (Ge and Blow 2010). Additionally, the GINS subunit Psf1 is phosphorylated by ATR in response to $\mathrm{HU}$; thus, the checkpoint may function to regulate replisome function rather than stability (De Piccoli et al. 2012).

If stalled forks cannot be restarted, the replication machinery can disassemble. Several events can ensue at the fork. Electron microscopy (EM) studies in yeast found that HU treatment in the absence of Rad53/Chk2 leads to the accumulation of ssDNA at replication forks and reversed forks (Sogo et al. 2002). These reversed forks are known as "chicken foot" structures. Fork reversal was long thought to be the result of failed checkpoint response to fork stalling, but a recent study in human cell culture demonstrated that fork reversal is a common response to various replication perturbations when the checkpoint is intact (Zellweger et al. 2015). Fork reversal also is observed at trinucleotide repeats (Follonier et al. 2013), suggesting that chicken foot structures can form during unperturbed replication at hard to replicate sequences. Formation of reversed forks is dependent on PARP-1 regulation of the RECQ1 helicase as well as Rad51 (Zellweger et al. 2015). Other studies additionally have demonstrated a role for Rad51 and other homologous recombination (HR) components in fork stabilization independent of DSB repair (Lomonosov et al. 2003; Petermann et al. 2010; Schlacher et al. 2011; Hashimoto et al. 2012).

Cleavage of stalled or regressed forks can cause the fork to collapse and generate single-ended DSBs (see Fig. 3B) that require the DSB repair response. Several components are recruited to the break site upon DSB formation. Mre11-Rad50-Nbs1 (MRN; MRX in yeast) binds to DSBs and recruits ATM (Lee and Paull 2005). Inactive ATM forms a dimer; recruitment to DSBs leads to autophosphorylation and dimer dissociation, activating the kinase activity of the two monomers (Bakkenist and Kastan 2003). Upon activation, ATM phosphorylates multiple DSB response targets, including Chk2 and the histone variant H2AX (Rogakou et al. 1998; Ahn et al. 2000; Matsuoka et al. 2000). H2AX is phosphorylated in response to DSB formation for up to several megabases on either side of the break in mammalian cells (Rogakou et al. 1998; Madigan et al. 2002; Iacovoni et al. 2010), and $\gamma \mathrm{H} 2 \mathrm{AX}$ serves as a docking platform for DSB repair proteins (Celeste et al. 2002, 2003; Ward et al. 2003). Although Saccharomyces cerevisiae lacks an H2AX variant, either of the two H2A histones can be phosphorylated on Ser129 in response to DNA damage for up to 50 $\mathrm{kb}$ on either side of a DSB (Redon et al. 2003).

We first discuss the multiple pathways to repair DSBs in which two ends on either side of the DSB participate in the repair event. Pathway decision is ultimately determined by resection of the ends resulting from the DSB, with long 3' overhangs facilitating HR (Fig. 2). Both the phase of the cell cycle and levels of accessory proteins influence whether nucleases have access to the DSB, thus dictating which repair pathway predominates. During $S$ phase, when replication forks are actively elongating daughter DNA strands, S-phase CDK activity promotes break resection (Aylon et al. 2004; Ferreira and Cooper 2004; Ira et al. 2004; Bennardo et al. 2008; Yun and Hiom 2009; Chen et al. 2011; Tomimatsu et al. 2014). CDK promotes activity of the exonuclease CtIP, which, with MRN, mediates limited resection of the DSB ends to expose $3^{\prime}$ ssDNA overhangs (Bennardo et al. 2008; Yun and Hiom 2009). Extensive break resection also is mediated by CDK activity via EXO1 (Chen et al. 2011; Tomimatsu et al. 2014). In addition to CDK regulation, resection is dictated by competition between BRCA1 and 53BP1 for access to the DSB. 


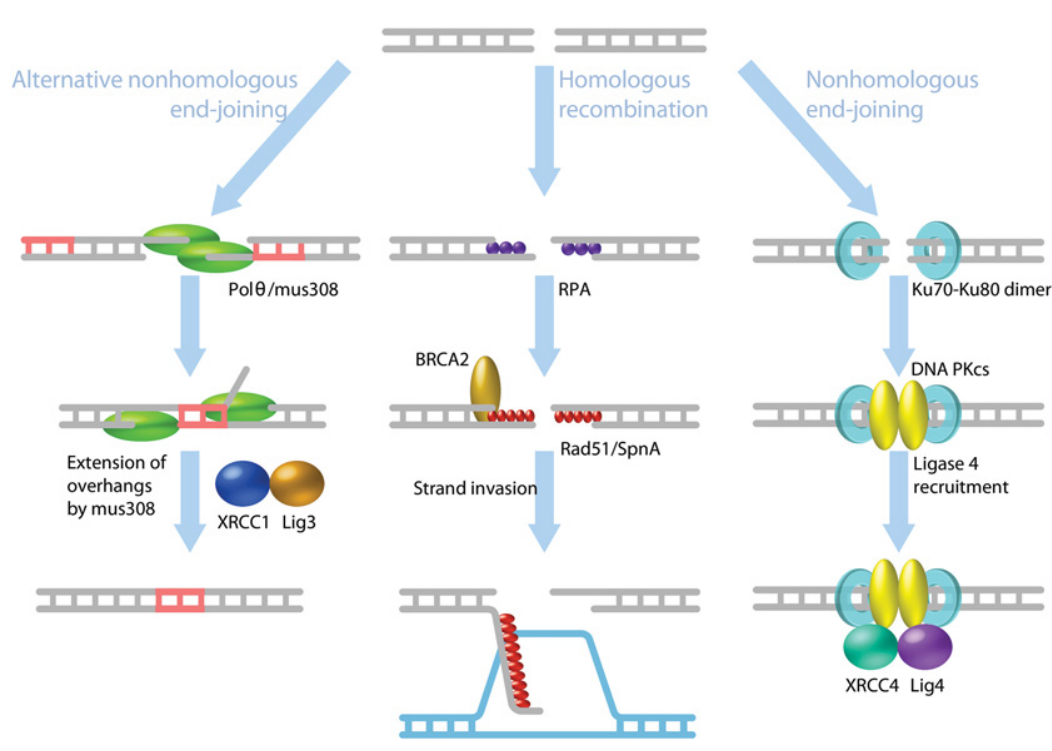

Figure 2. Pathways of DSB repair. Resection of the DSB commits repair to HR or alternative end-joining (alt-EJ) repair pathways. (Left) Alt-EJ by microhomology-mediated end-joining (MMEJ) requires $\operatorname{Pol} \theta$ to align or template short microhomologies, generating deletions and insertions. The ends are then ligated together by the Ligase III (Lig3)/XRCC1 complex. (Middle) HR repair requires BRCA2 to recruit Rad51 and facilitates filament formation along the resected DNA. Rad51 filaments search for homologous sequences and initiate strand invasion to restore the exact sequence to the break site. (Right) Resection is blocked in nonhomologous end-joining (NHEJ) by Ku70-80 binding. The Ku70-80 heterodimer recruits the DNA-dependent protein kinase catalytic subunit (DNA-PKcs), and this complex brings the broken DNA ends together. The XRCC4-DNA Ligase IV (Lig4) complex is recruited and catalyzes DSB ligation. (Illustration by Steven Lee, http://www.graphiko.com.)
Both BRCA1 and 53BP1 are concentrated at DSBs by $\gamma \mathrm{H} 2 \mathrm{AX}$ (Celeste et al. 2003; Ward et al. 2003) but also antagonize each other's recruitment (Escribano-Diaz et al. 2013). BRCA1 forms a complex with CtIP during $S$ and G2 and promotes DSB resection (Yu and Chen 2004; Yun and Hiom 2009; Escribano-Diaz et al. 2013). During G1 of the cell cycle, 53BP1 prevents BRCA1 focus formation and thereby may inhibit CtIP access to DSBs to thus block resection-mediated repair (Escribano-Diaz et al. 2013). It therefore seems likely that the antagonistic relationship between 53BP1 and BRCA1 helps to integrate cell cycle regulation of DSB repair pathway choice.

Limited resection by MRN and CtIP commits the break to HR or alternative end-joining (alt-EJ) repair pathways (Yun and Hiom 2009; Truong et al. 2013). More extensive resection by EXO is required for HR repair (Yun and Hiom 2009; Truong et al. 2013). During HR repair, ssDNA exposed by resection is coated by Rad51, which mediates the search for homologous sequences and strand invasion for template repair (Fig. 2; McIlwraith et al. 2000). If only limited resection of the break occurs, alt-EJ can be used to repair the break (Yun and Hiom 2009; Truong et al. 2013). One form of alt-EJ is microhomology-mediated end-joining (MMEJ), which joins together microhomologies exposed by resection. MMEJ requires Pol $\theta$, which binds to ssDNA on both ends of a DSB and aligns short 4- to 10base-pair microhomology sequences (Fig. 2; Chan et al. 2010; Kent et al. 2015; Mateos-Gomez et al. 2015). Microhomologies also can be generated by $\operatorname{Pol} \theta$, resulting in insertions templated from sequences outside the break site (Chan et al. 2010; Yu and McVey 2010; Hogg et al. 2012; Kent et al. 2015). MMEJ is a highly error-prone pathway, generating deletions and insertions at the break site from microhomology alignment and extension or complex chromosome rearrangements /Chan et al. 2010; Yu and McVey 2010; Hogg et al. 2012; Kent et al. 2015; Mateos-Gomez et al. 2015; Sakofsky et al. 2015).

The nonhomologous end-joining (NHEJ) repair pathway directly joins the two broken ends of a DSB and actively prevents $3^{\prime}$ resection (Fig. 2). The blunt DNA ends are bound by the Ku70-80 heterodimer and DNA-dependent protein kinase catalytic subunit (DNA-PKcs), which prevent resection and promote association of the broken ends (Dvir et al. 1992; Gottlieb and Jackson 1993; Yoo and Dynan 1999; Pierce et al. 2001; Walker et al. 2001; Graham et al. 2016). Ligase IV (Lig4) catalyzes ligation of the DSB ends, and this reaction is enhanced by XRCC4 (Grawunder et al. 1997). Direct ligation of the broken ends often generates small deletions at the break site (Jeggo 1998), and thus NHEJ is considered an error-prone repair mechanism. NHEJ is active throughout the cell cycle, but competition from resection-mediated pathways during S and G2 make it more prevalent during G1.

Break-induced replication (BIR) is a subtype of $\mathrm{HR}$ repair that can account for repair of a DSB with only one end. It was characterized in yeast following the observation that one end of a broken chromosome can copy a homologous template to the end of the chromosome. BIR requires many of the components present at S-phase replication forks but does not require the pre-RC components ORC or Cdc6 (Lydeard et al. 2010). These results support the hypothesis that BIR establishes processive replication forks in the absence of an origin. In addition to canonical fork requirements, the appearance of BIR repair products depends on the nonessential Pol $\delta$ subunit Pol32 (Lydeard et al. 2007), and the Pif1 helicase is required for long-range synthesis during BIR (Saini et al. 2013; Wilson et al. 2013; Vasianovich et al. 2014).

BIR also was demonstrated in human cell lines under conditions of replication stress, suggesting that it is used to repair collapsed replication forks (Costantino et al. 2014). The investigators found that BIR generated duplications and rearrangements. A model for the generation of copy number variations proposed a form of BIR that relies on microhomology annealing, termed microhomologymediated BIR (MMBIR), in repair of collapsed replication forks (Hastings et al. 2009). Complex rearrangements and copy number variations consistent with BIR and 
MMBIR are observed across human cancers and other genomic diseases (Hastings et al. 2009).

\section{Rereplication: how origin deregulation impairs fork integrity}

Origin refiring in a single $S$ phase activates the DNA damage checkpoint, generates DSBs, and causes DNA fragmentation (Mihaylov et al. 2002; Melixetian et al. 2004; Zhu et al. 2004; Archambault et al. 2005; Green and Li 2005; Davidson et al. 2006; Zhu and Dutta 2006; Finn and Li 2013; Neelsen et al. 2013), making rereplication a highly genotoxic event. The damage caused by origin refiring appears to arise from problems at the rereplication forks. Rereplication forks exhibit inhibited elongation and progress only 30-35 kb from the origin in yeast (Nguyen et al. 2001). Consistent with this observation, rereplication does not result in full replication of the genome and generates cells with ploidies between integral doubling values (Melixetian et al. 2004; Zhu et al. 2004; Green and Li 2005). If the DNA damage checkpoint is blocked, cells enter mitosis with partially rereplicated DNA, resulting in cells with sub-G1 ploidy (Mihaylov et al. 2002) and chromosome breaks and fusions (Melixetian et al. 2004).

To prevent this catastrophic damage, replication initiation is tightly regulated with the cell cycle to ensure that each origin fires only once per cell cycle (Tanaka and Araki 2013). In budding yeast, CDK activity prevents rereplication by inhibiting multiple components of the pre-RC at several levels of regulation. Phosphorylation of Orc2 and Orc6 by CDK prevents pre-RC formation (Arias and Walter 2007). CDK phosphorylation events inhibit cdc6 transcription. Direct phosphorylation of Cdc6 promotes ubiquitination by SCF to lead to its degradation by the proteasome from late G1 to $S$ phase and then, in mitosis, prevents Cdc6 from loading Mcm2-7 (Arias and Walter 2007). Finally, CDK phosphorylation exports Cdt1 and Mcm2-7 from the nucleus (Arias and Walter 2007).

CDK activity also prevents rereplication in metazoans by targeting multiple pre-RC components, although the mechanisms differ between organisms. One common and major regulator of pre-RC activity is geminin, which binds to and sequesters Cdt1 to prevent Mcm2-7 from being loaded at origins (Arias and Walter 2007). Depletion of geminin is sufficient to induce rereplication in Drosophila and human cultured cells (Mihaylov et al. 2002; Melixetian et al. 2004; Zhu et al. 2004; Zhu and Dutta 2006). Overexpression of its target, Cdt1, in human cells and Drosophila and addition of recombinant Cdt 1 to Xenopus cell extracts also cause rereplication (Arias and Walter 2007).

DSBs and chromosome fragmentation generated during rereplication are consistent with predicted products of head-to-tail collisions between adjacent replication forks (Fig. 3A; Davidson et al. 2006). If a leading strand reaches a region with unligated Okazaki fragments on a fork in front of it, this results in a DSB (Fig. 3B). This is supported by the observation that broken DNA fragments are generated around an origin after rereplication is induced (Finn
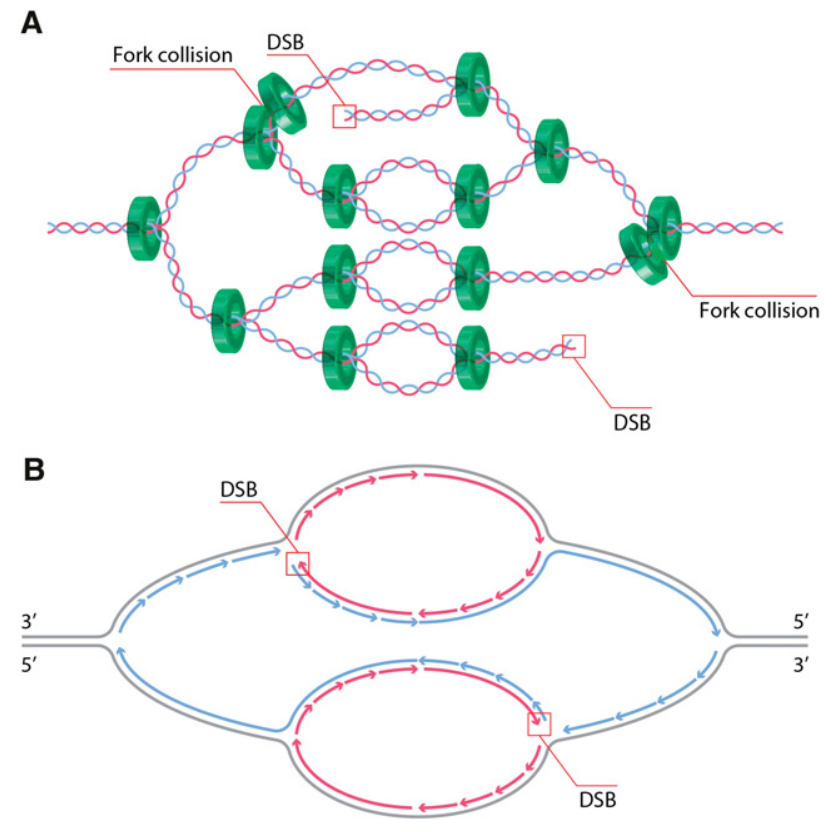

Figure 3. The fork collision model of DSB generation by rereplication. (A) Collisions between two replication forks on the same DNA duplex (green) would generate a DSB behind the second replication fork (arrows). Multiple origin reinitiations would increase the frequency of fork collisions and thus the number DSBs formed. Fork collisions are expected to be stochastic and may occur at only a subset of forks, as shown here. $(B)$ One proposed mechanism of DSB formation. If the leading strand (red) from a second fork collides with unligated Okazaki fragments on the lagging strand of an earlier fork (blue), a DSB results. Note that, although this is single-end DSB, fork collisions on opposite sides of the origin could generate two ends that could be joined by NHEJ. Other mechanisms such as exonuclease cleavage or steric breakage of the DNA also could generate additional DSB ends. (Illustration by Steven Lee, http://www.graphiko.com.)

and Li 2013). The pattern of repeat expansion during rereplication also is consistent with a "forks chasing forks" model of DSB formation (Green et al. 2010; Finn and Li 2013). Such collisions require that rereplication forks can progress faster along the newly synthesized DNA and thus catch up with the forks in front of them (Davidson et al. 2006). Indeed, nascent DNA is in an immature chromatin state for up to $20 \mathrm{~min}$ after replication and is more susceptible to nuclease degradation (Hildebrand and Walters 1976). Immature chromatin behind the first replication fork could thus be easier to disassemble and more susceptible to breaks as the rereplication forks arrive.

Strong evidence for the fork collision model (Fig. 3) was provided by recent studies in Drosophila follicle cells. The follicle cells of Drosophila melanogaster undergo rereplication from defined origins as a developmental strategy to enhance protein production by gene amplification. Rereplication occurs at six loci, termed Drosophila amplicons in follicle cells (DAFCs) (Kim et al. 2011). The precise timing and location of origin firing at the DAFCs enables isolation of replication forks at specific points after origin 
initiation and real-time tracking of fork progression (Claycomb and Orr-Weaver 2005). Additionally, replication forks can be visualized directly by introducing a nucleotide analog (Claycomb and Orr-Weaver 2005), providing the necessary resolution to observe events occurring at sites of active replication. Analysis of rereplication damage at the DAFCs revealed that the DSB marker $\gamma \mathrm{H} 2 \mathrm{Av}$ tracks with EdU at the DAFCs and is dependent on ATR and ATM activity (Alexander et al. 2015). These data are supported by ChIP-seq (chromatin immunoprecipitation [ChIP] combined with high-throughput sequencing) measurements showing that $\gamma \mathrm{H} 2 \mathrm{Av}$ is enriched over positions of active rereplication forks in the follicle cells (Alexander et al. 2015). The DAFC system thus has made it possible to detect damage present at known positions of rereplication at defined points in time after the onset of origin refiring with a resolution not possible in previously studied systems. Additionally, the data indicate that DNA damage and DSBs are formed at the active replication forks, where head-to-tail collisions could occur.

Other data suggest that DSBs formed by rereplication occur in the absence of fork collisions. RNAi depletion of Emi1 (an APC/C inhibitor that prevents geminin degradation during S and G2) (Machida and Dutta 2007) in human cells in culture generates ssDNA gaps along the DNA before detectable rereplication occurs (Neelsen et al. 2013). The investigators proposed that deregulated origin firing leads to unrepaired gaps in the first round of replication, which cause fork collapse and DNA fragmentation when rereplication forks meet these gaps on the template strand. Gaps also were reported when recombinant Cdt 1 was added to Xenopus extracts, but the appearance of gaps in relation to the onset of rereplication was not reported (Neelsen et al. 2013). It is therefore possible that the cause of DSBs during rereplication is dependent on the mechanism and timing of origin deregulation.

The generation of DSBs during rereplication poses the question of how these breaks are repaired. Although fork collision results in a DSB with a single end, DSBs with two ends can be generated if fork collision occurs on both sides of the origin (Fig. 3B) and by several other mechanisms detailed by Truong et al. (2014). Thus, the pathways for repair of DSBs with two ends (Fig. 2) as well as BIR potentially can be involved in repair. In human cells in culture, Rad51 foci form after geminin depletion (Melixetian et al. 2004; Zhu and Dutta 2006), suggesting that the HR repair pathway is activated to repair broken forks. Another study using human cells reported that 53BP1 foci appear overlapping with $\gamma \mathrm{H} 2 \mathrm{AX}$ when rereplication is induced, suggesting NHEJ repair (Neelsen et al. 2013). However, these studies only reported on markers of one repair pathway and did not test whether there is a preferred mechanism of repair. In two human cell culture lines, knockdown of the HR components Rad51, BRCA1, and CtIP reduced cell proliferation when Cdt 1 was overexpressed, whereas knockdown of the NHEJ components $\mathrm{Ku} 70$ and XRCC4 had no effect (Truong et al. 2014). Interestingly, knockdown of the MMEJ component Lig3 also reduced proliferation, although to a lesser extent than HR factors (Truong et al. 2014). Using GFP reporter con- structs for $\mathrm{HR}$ and MMEJ repair after rereplication, the investigators found that the percentage of GFP-positive cells increases upon Cdt1 overexpression; this frequency is not altered by knockdown of Ku70 or XRCC4, suggesting that NHEJ does not compete for repair in these cells (Truong et al. 2014).

Evidence from studies in S. cerevisiae also suggests that multiple pathways can repair rereplication forks. The HR pathway mutants rad52 and rad59 are synthetically lethal in rereplicating strains, as are the three components of the MRX complex (mre11, rad50, and xrs1) (Archambault et al. 2005). In budding yeast, the MRX complex is involved in both NHEJ and HR repair (D'Amours and Jackson 2002). Notably, mutants with lesions in the NHEJ components yku70, yku80, and dnl4 (lig4) are viable in rereplicating strains, suggesting that MRX is functioning in HR repair during rereplication (Archambault et al. 2005). However, a recent study showed that the frequency of rereplication-induced aneuploidy is halved in rad52 mutants and tripled in dnl4 mutants; these results demonstrate that both the HR and NHEJ pathways are active and compete to repair DSBs generated by rereplication (Hanlon and Li 2015). Finally, repeat expansion after rereplication in S. cerevisiae occurs via single-strand annealing (SSA) repair and is genetically dependent on rad52, rad1, and msh3 but not rad51 or dnl4 (Green et al. 2010; Finn and Li 2013).

Use of multiple pathways in rereplication-induced DSB repair also is supported by studies in Drosophila follicle cells. Multiple rereplication events at the DAFCs generate gradients of amplification, which are easily visualized by array comparative genomic hybridization $(\mathrm{aCGH})$ analysis (Kim et al. 2011). The shape of the amplification gradients generated by aCGH is reflective of replication fork progression, in which rapid decreases in copy number along the gradients indicate that fork progression is impaired. aCGH thus can be used to measure fork movement in the absence of various DSB repair components. Because unrepaired DSBs within the DAFCs block all subsequent replication forks on the same strand from moving beyond the break site, removal of DSB repair pathways used during rereplication reduces overall fork progression. Changes in global fork progression were quantified by halfmaximum distance analysis, which measures the distance between the left and right sides of half the maximum copy number of the aCGH gradients (Alexander et al. 2015). This approach was used to analyze mutants in DSB repair pathways. NHEJ is required for repair of these DSBs, as the absence of the NHEJ factor Lig4 inhibits fork progression across the DAFCs (Alexander et al. 2015). Additionally, the MMEJ component Pol $\theta$ is required for complete fork progression at only some of the DAFCs, revealing that the use of this pathway for rereplication DSB repair is site-specific (Alexander et al. 2016). In contrast, the absence of the HR components Brca2 and Rad51 enhances fork movement (Alexander et al. 2016). These results suggest that HR is active but cannot productively contribute to DSB repair before the end of amplification, which occurs over a 7.5-h time in development. As a consequence, HR appears to compete with and impede NHEJ repair. 
There is a possible contribution of BIR at the DAFCs because replication fork progression is reduced in pol32 and pif1 mutants (Alexander et al. 2016), but because these two proteins participate in other aspects of fork progression, it cannot be excluded that these functions account for the mutant phenotype (Alexander et al. 2016). Together, the analysis of DAFCs suggests that DSB repair pathway choice following rereplication is governed by genomic position, reaction kinetics, and repair pathway competition.

\section{Conclusions and outlook}

Recent studies in yeast and Drosophila have permitted the analysis of rereplication at specific genomic sites and thus demonstrated directly that rereplication can lead to fork collision and formation of DSBs. Although there are parallels between these fork collision events and fork stalling during normal DNA replication, such as the involvement of DNA damage signaling pathways, the extent to which repair mechanisms are shared remains to be determined. For example, it is unknown whether fork reversal occurs at rereplication fork collision sites and whether it affects fork stability. The analyses of rereplication suggest that a variety of pathways can be used to repair DSBs resulting from fork collision. Resection-dependent pathways, including HR, SSA, and MMEJ, are the most commonly observed, consistent with rereplication occurring in S and G2 phases of the cell cycle, when resection is most efficient. However, NHEJ repair also has been reported (Neelsen et al. 2013; Alexander et al. 2015; Hanlon and Li 2015). Therefore, as with general DSBs, pathway choice for repair of rereplication DSBs could be the result of pathway competition influenced by the cell cycle phase and exonuclease access to the break site.

Mounting evidence suggests that repair choice influences the consequences for genome instability. Refiring within repetitive sequences is repaired by SSA and leads to copy number expansions (Green et al. 2010; Finn and Li 2013). Rereplication near centromeres increases the rate of aneuploidy if forks are repaired by HR, whereas NHEJ seems to protect these cells from missegregation (Hanlon and $\mathrm{Li}$ 2015). These types of chromosomal aberrations are common across numerous human cancers (Abbas et al. 2013). Additionally, Cdt1 overexpression drives oncogenic transformation in cell culture and tumor formation in mouse models and is observed in various human cancer cell lines (Arentson et al. 2002; Karakaidos et al. 2004; Xouri et al. 2004; Seo et al. 2005). Together, these observations strongly suggest that the same mechanisms used to artificially induce rereplication in the laboratory and the resulting genome instability are physiologically relevant to cancer progression. However, rereplication has not been observed directly at specific sites in cancer cells.

Technological advances such as iPOND and rapidly improving deep sequencing platforms could help to shed light on which repair mechanisms are activated during rereplication and the resulting repair products. Proteomics would reveal which repair proteins are recruited to rereplication forks, providing a list of competing repair mechanisms. The continued study of model systems such as $S$. cerevisiae and the Drosophila DAFCs will make it possible to dissect both the mechanisms of rereplication fork repair and the consequences of pathway choice on genome stability.

\section{Acknowledgments}

We thank Steve Bell and Johannes Walter for comments on an early version of this review. This work was supported by National Institutes of Health grants GM57960 and 118098 to T.O.-W. T.O.W. is an American Cancer Society Research Professor.

\section{References}

Abbas T, Keaton MA, Dutta A. 2013. Genomic instability in cancer. Cold Spring Harb Perspect Biol 5: a012914.

Ahn JY, Schwarz JK, Piwnica-Worms H, Canman CE. 2000. Threonine 68 phosphorylation by ataxia telangiectasia mutated is required for efficient activation of Chk2 in response to ionizing radiation. Cancer Res 60: 5934-5936.

Alabert C, Groth A. 2012. Chromatin replication and epigenome maintenance. Nat Rev Mol Cell Biol 13: 153-167.

Alabert C, Bukowski-Wills JC, Lee SB, Kustatscher G, Nakamura K, de Lima Alves F, Menard P, Mejlvang J, Rappsilber J, Groth A. 2014. Nascent chromatin capture proteomics determines chromatin dynamics during DNA replication and identifies unknown fork components. Nat Cell Biol 16: 281-293.

Alexander JL, Barrasa MI, Orr-Weaver TL. 2015. Replication fork progression during re-replication requires the DNA damage checkpoint and double-strand break repair. Curr Biol 25: 1654-1660.

Alexander JL, Beagan K, Orr-Weaver TL, McVey M. 2016. Multiple mechanisms contribute to double-strand break repair at rereplication forks in Drosophila follicle cells. Proc Natl Acad Sci (in press).

Andreyeva EN, Kolesnikova TD, Belyaeva ES, Glaser RL, Zhimulev IF. 2008. Local DNA underreplication correlates with accumulation of phosphorylated $\mathrm{H} 2 \mathrm{Av}$ in the Drosophila melanogaster polytene chromosomes. Chromosome Res 16: 851-862.

Archambault V, Ikui AE, Drapkin BJ, Cross FR. 2005. Disruption of mechanisms that prevent rereplication triggers a DNA damage response. Mol Cell Biol 25: 6707-6721.

Arentson E, Faloon P, Seo J, Moon E, Studts JM, Fremont DH, Choi K. 2002. Oncogenic potential of the DNA replication licensing protein CDT1. Oncogene 21: 1150-1158.

Arias EE, Walter JC. 2007. Strength in numbers: preventing rereplication via multiple mechanisms in eukaryotic cells. Genes Dev 21: 497-518.

Aylon Y, Liefshitz B, Kupiec M. 2004. The CDK regulates repair of double-strand breaks by homologous recombination during the cell cycle. EMBO I 23: 4868-4875.

Bakkenist CJ, Kastan MB. 2003. DNA damage activates ATM through intermolecular autophosphorylation and dimer dissociation. Nature 421: 499-506.

Belyaeva ES, Zhimulev IF, Volkova EI, Alekseyenko AA, Moshkin YM, Koryakov DE. 1998. Su(UR)ES: a gene suppressing DNA underreplication in intercalary and pericentric heterochromatin of Drosophila melanogaster polytene chromosomes. Proc Natl Acad Sci 95: 7532-7537. 
Bennardo N, Cheng A, Huang N, Stark JM. 2008. AlternativeNHEJ is a mechanistically distinct pathway of mammalian chromosome break repair. PLoS Genet 4: e1000110.

Besnard E, Babled A, Lapasset L, Milhavet O, Parrinello H, Dantec C, Marin JM, Lemaitre JM. 2012. Unraveling cell type-specific and reprogrammable human replication origin signatures associated with G-quadruplex consensus motifs. Nat Struct Mol Biol 19: 837-844.

Byun TS, Pacek M, Yee MC, Walter JC, Cimprich KA. 2005. Functional uncoupling of MCM helicase and DNA polymerase activities activates the ATR-dependent checkpoint. Genes Dev 19: $1040-1052$.

Celeste A, Petersen S, Romanienko PJ, Fernandez-Capetillo O, Chen HT, Sedelnikova OA, Reina-San-Martin B, Coppola V, Meffre E, Difilippantonio MJ, et al. 2002. Genomic instability in mice lacking histone H2AX. Science 296: 922-927.

Celeste A, Fernandez-Capetillo O, Kruhlak MJ, Pilch DR, Staudt DW, Lee A, Bonner RF, Bonner WM, Nussenzweig A. 2003. Histone H2AX phosphorylation is dispensable for the initial recognition of DNA breaks. Nat Cell Biol 5: 675-679.

Chan SH, Yu AM, McVey M. 2010. Dual roles for DNA polymerase $\theta$ in alternative end-joining repair of double-strand breaks in Drosophila. PLoS Genet 6: e1001005.

Chen X, Niu H, Chung WH, Zhu Z, Papusha A, Shim EY, Lee SE, Sung P, Ira G. 2011. Cell cycle regulation of DNA doublestrand break end resection by Cdk1-dependent Dna2 phosphorylation. Nat Struct Mol Biol 18: 1015-1019.

Claycomb JM, Orr-Weaver TL. 2005. Developmental gene amplification: insights into DNA replication and gene expression. Trends Genet 21: 149-162.

Costantino L, Sotiriou SK, Rantala JK, Magin S, Mladenov E, Helleday T, Haber JE, Iliakis G, Kallioniemi OP, Halazonetis TD. 2014. Break-induced replication repair of damaged forks induces genomic duplications in human cells. Science 343: 88-91.

D'Amours D, Jackson SP. 2002. The Mre11 complex: at the crossroads of DNA repair and checkpoint signalling. Nat Rev Mol Cell Biol 3: 317-327.

Davidson IF, Li A, Blow JJ. 2006. Deregulated replication licensing causes DNA fragmentation consistent with head-to-tail fork collision. Mol Cell 24: 433-443.

Debatisse M, Le Tallec B, Letessier A, Dutrillaux B, Brison O. 2012. Common fragile sites: mechanisms of instability revisited. Trends Genet 28: 22-32.

Delacroix S, Wagner JM, Kobayashi M, Yamamoto K, Karnitz LM. 2007. The Rad9-Hus1-Rad1 (9-1-1) clamp activates checkpoint signaling via TopBP1. Genes Dev 21: 1472-1477.

De Piccoli G, Katou Y, Itoh T, Nakato R, Shirahige K, Labib K. 2012. Replisome stability at defective DNA replication forks is independent of S phase checkpoint kinases. Mol Cell 45: 696-704.

Duxin JP, Dewar JM, Yardimci H, Walter JC. 2014. Repair of a DNA-protein crosslink by replication-coupled proteolysis. Cell 159: 346-357.

Dvir A, Peterson SR, Knuth MW, Lu H, Dynan WS. 1992. Ku autoantigen is the regulatory component of a template-associated protein kinase that phosphorylates RNA polymerase II. Proc Nat1 Acad Sci 89: 11920-11924.

Escribano-Diaz C, Orthwein A, Fradet-Turcotte A, Xing M, Young JT, Tkac J, Cook MA, Rosebrock AP, Munro M, Canny $\mathrm{MD}$, et al. 2013. A cell cycle-dependent regulatory circuit composed of 53BP1-RIF1 and BRCA1-CtIP controls DNA repair pathway choice. Mol Cell 49: 872-883.
Ferreira MG, Cooper JP. 2004. Two modes of DNA double-strand break repair are reciprocally regulated through the fission yeast cell cycle. Genes Dev 18: 2249-2254.

Finn KJ, Li JJ. 2013. Single-stranded annealing induced by reinitiation of replication origins provides a novel and efficient mechanism for generating copy number expansion via non-allelic homologous recombination. PLoS Genet 9: e1003192.

Follonier C, Oehler J, Herrador R, Lopes M. 2013. Friedreich's ataxia-associated GAA repeats induce replication-fork reversal and unusual molecular junctions. Nat Struct Mol Biol 20: 486-494.

Fu YV, Yardimci H, Long DT, Ho TV, Guainazzi A, Bermudez VP, Hurwitz J, van Oijen A, Scharer OD, Walter JC. 2011. Selective bypass of a lagging strand roadblock by the eukaryotic replicative DNA helicase. Cell 146: 931-941.

Ge XQ, Blow IJ. 2010. Chk1 inhibits replication factory activation but allows dormant origin firing in existing factories. I Cell Biol 191: 1285-1297.

Gerhardt J, Tomishima MJ, Zaninovic N, Colak D, Yan Z, Zhan Q, Rosenwaks Z, Jaffrey SR, Schildkraut CL. 2014. The DNA replication program is altered at the FMR1 locus in fragile X embryonic stem cells. Mol Cell 53: 19-31.

Gottlieb TM, Jackson SP. 1993. The DNA-dependent protein kinase: requirement for DNA ends and association with $\mathrm{Ku}$ antigen. Cell 72: 131-142.

Graham TG, Walter JC, Loparo JJ. 2016. Two-stage synapsis of DNA ends during non-homologous end joining. Mol Cell 61: 850-858.

Grawunder U, Wilm M, Wu X, Kulesza P, Wilson TE, Mann M, Lieber MR. 1997. Activity of DNA ligase IV stimulated by complex formation with XRCC4 protein in mammalian cells. Nature 388: 492-495.

Green BM, Li JJ. 2005. Loss of rereplication control in Saccharomyces cerevisiae results in extensive DNA damage. Mol Biol Cell 16: 421-432.

Green BM, Finn KJ, Li JJ. 2010. Loss of DNA replication control is a potent inducer of gene amplification. Science 329: 943-946.

Hanlon SL, Li JJ. 2015. Re-replication of a centromere induces chromosomal instability and aneuploidy. PLoS Genet 11: e1005039.

Hashimoto Y, Puddu F, Costanzo V. 2012. RAD51- and MRE11-dependent reassembly of uncoupled CMG helicase complex at collapsed replication forks. Nat Struct Mol Biol 19: 17-24.

Hastings PI, Ira G, Lupski JR. 2009. A microhomology-mediated break-induced replication model for the origin of human copy number variation. PLoS Genet 5: e1000327.

Hildebrand CE, Walters RA. 1976. Rapid assembly of newly synthesized DNA into chromatin subunits prior to joining to small DNA replication intermediates. Biochem Biophys Res Commun 73: 157-163.

Hogg M, Sauer-Eriksson AE, Johansson E. 2012. Promiscuous DNA synthesis by human DNA polymerase $\theta$. Nucleic Acids Res 40: 2611-2622.

Hoshina S, Yura K, Teranishi H, Kiyasu N, Tominaga A, Kadoma H, Nakatsuka A, Kunichika T, Obuse C, Waga S. 2013. Human origin recognition complex binds preferentially to Gquadruplex-preferable RNA and single-stranded DNA. J Biol Chem 288: 30161-30171.

Iacovoni JS, Caron P, Lassadi I, Nicolas E, Massip L, Trouche D, Legube G. 2010. High-resolution profiling of $\gamma \mathrm{H} 2 \mathrm{AX}$ around DNA double strand breaks in the mammalian genome. EMBO J 29: 1446-1457. 
Ira G, Pellicioli A, Balijia A, Wang X, Fiorani S, Carotenuto W, Liberi G, Bressan D, Wan L, Hollingsworth NM, et al. 2004. DNA end resection, homologous recombination and DNA damage checkpoint activation require CDK1. Nature 431: 1011-1017.

Jeggo PA. 1998. Identification of genes involved in repair of DNA double-strand breaks in mammalian cells. Radiat Res 150: S80-S91.

Johnson A, O'Donnell M. 2005. Cellular DNA replicases: components and dynamics at the replication fork. Annu Rev Biochem 74: 283-315.

Karakaidos P, Taraviras S, Vassiliou LV, Zacharatos P, Kastrinakis NG, Kougiou D, Kouloukoussa M, Nishitani H, Papavassiliou AG, Lygerou Z, et al. 2004. Overexpression of the replication licensing regulators hCdt 1 and hCdc 6 characterizes a subset of non-small-cell lung carcinomas: synergistic effect with mutant p53 on tumor growth and chromosomal instability-evidence of E2F-1 transcriptional control over hCdt1. Am J Pathol 165: 1351-1365.

Kent T, Chandramouly G, McDevitt SM, Ozdemir AY, Pomerantz RT. 2015. Mechanism of microhomology-mediated end-joining promoted by human DNA polymerase $\theta$. Nat Struct Mol Biol 22: 230-237.

Kim JC, Nordman J, Xie F, Kashevsky H, Eng T, Li S, MacAlpine DM, Orr-Weaver TL. 2011. Integrative analysis of gene amplification in Drosophila follicle cells: parameters of origin activation and repression. Genes Dev 25: 1384-1398.

Kliszczak AE, Rainey MD, Harhen B, Boisvert FM, Santocanale C. 2011. DNA mediated chromatin pull-down for the study of chromatin replication. Sci Rep 1: 95.

Kumagai A, Lee J, Yoo HY, Dunphy WG. 2006. TopBP1 activates the ATR-ATRIP complex. Cell 124: 943-955.

Lee JH, Paull TT. 2005. ATM activation by DNA double-strand breaks through the Mre11-Rad50-Nbs1 complex. Science 308: 551-554.

Lee J, Kumagai A, Dunphy WG. 2007. The Rad9-Hus1-Rad1 checkpoint clamp regulates interaction of TopBP1 with ATR. J Biol Chem 282: 28036-28044.

Liu Q, Guntuku S, Cui XS, Matsuoka S, Cortez D, Tamai K, Luo G, Carattini-Rivera S, DeMayo F, Bradley A, et al. 2000. Chk1 is an essential kinase that is regulated by Atr and required for the G(2)/M DNA damage checkpoint. Genes Dev 14: 1448-1459.

Liu G, Chen X, Leffak M. 2013. Oligodeoxynucleotide binding to (CTG). (CAG) microsatellite repeats inhibits replication fork stalling, hairpin formation, and genome instability. Mol Cell Biol 33: 571-581.

Lomonosov M, Anand S, Sangrithi M, Davies R, Venkitaraman AR. 2003. Stabilization of stalled DNA replication forks by the BRCA2 breast cancer susceptibility protein. Genes DeV 17: 3017-3022.

London TB, Barber LJ, Mosedale G, Kelly GP, Balasubramanian S, Hickson ID, Boulton SJ, Hiom K. 2008. FANCJ is a structurespecific DNA helicase associated with the maintenance of genomic G/C tracts. J Biol Chem 283: 36132-36139.

Lopez-Contreras AJ, Ruppen I, Nieto-Soler M, Murga M, Rodriguez-Acebes S, Remeseiro S, Rodrigo-Perez S, Rojas AM, Mendez J, Munoz J, et al. 2013. A proteomic characterization of factors enriched at nascent DNA molecules. Cell Rep 3: 1105-1116.

Lydeard JR, Jain S, Yamaguchi M, Haber JE. 2007. Break-induced replication and telomerase-independent telomere maintenance require Pol32. Nature 448: 820-823.

Lydeard JR, Lipkin-Moore Z, Sheu YJ, Stillman B, Burgers PM, Haber JE. 2010. Break-induced replication requires all essen- tial DNA replication factors except those specific for pre-RC assembly. Genes Dev 24: 1133-1144.

Machida YJ, Dutta A. 2007. The APC/C inhibitor, Emil, is essential for prevention of rereplication. Genes Dev 21: 184-194.

Madigan JP, Chotkowski HL, Glaser RL. 2002. DNA doublestrand break-induced phosphorylation of Drosophila histone variant $\mathrm{H} 2 \mathrm{Av}$ helps prevent radiation-induced apoptosis. $\mathrm{Nu}$ cleic Acids Res 30: 3698-3705.

Maizels N, Gray LT. 2013. The G4 genome. PLoS Genet 9: e1003468.

Makunin IV, Volkova EI, Belyaeva ES, Nabirochkina EN, Pirrotta V, Zhimulev IF. 2002. The Drosophila suppressor of underreplication protein binds to late-replicating regions of polytene chromosomes. Genetics 160: 1023-1034.

Mantiero D, Mackenzie A, Donaldson A, Zegerman P. 2011. Limiting replication initiation factors execute the temporal programme of origin firing in budding yeast. $E M B O I$ 30: 4805-4814.

Mateos-Gomez PA, Gong F, Nair N, Miller KM, Lazzerini-Denchi E, Sfeir A. 2015. Mammalian polymerase $\theta$ promotes alternative NHEJ and suppresses recombination. Nature 518: 254-257.

Matsuoka S, Rotman G, Ogawa A, Shiloh Y, Tamai K, Elledge SJ. 2000. Ataxia telangiectasia-mutated phosphorylates Chk2 in vivo and in vitro. Proc Natl Acad Sci 97: 10389-10394.

McIlwraith MJ, Van Dyck E, Masson JY, Stasiak AZ, Stasiak A, West SC. 2000. Reconstitution of the strand invasion step of double-strand break repair using human Rad51 Rad52 and RPA proteins. J Mol Biol 304: 151-164.

Mejlvang J, Feng Y, Alabert C, Neelsen KJ, Jasencakova Z, Zhao X, Lees M, Sandelin A, Pasero P, Lopes M, et al.2014. New histone supply regulates replication fork speed and PCNA unloading. J Cell Biol 204: 29-43.

Melixetian M, Ballabeni A, Masiero L, Gasparini P, Zamponi R, Bartek J, Lukas J, Helin K. 2004. Loss of geminin induces rereplication in the presence of functional p53. J Cell Biol 165: 473-482.

Mihaylov IS, Kondo T, Jones L, Ryzhikov S, Tanaka J, Zheng J, Higa LA, Minamino N, Cooley L, Zhang H. 2002. Control of DNA replication and chromosome ploidy by geminin and cyclin A. Mol Cell Biol 22: 1868-1880.

Mirkin EV, Mirkin SM. 2007. Replication fork stalling at natural impediments. Microbiol Mol Biol Rev 71: 13-35.

Neelsen KJ, Zanini IM, Mijic S, Herrador R, Zellweger R, Ray Chaudhuri A, Creavin KD, Blow JJ, Lopes M. 2013. Deregulated origin licensing leads to chromosomal breaks by rereplication of a gapped DNA template. Genes Dev 27: 2537-2542.

Nelson DM, Ye X, Hall C, Santos H, Ma T, Kao GD, Yen TJ, Harper JW, Adams PD. 2002. Coupling of DNA synthesis and histone synthesis in S phase independent of cyclin/cdk2 activity. Mol Cell Biol 22: 7459-7472.

Nguyen VQ, Co C, Li JJ. 2001. Cyclin-dependent kinases prevent DNA re-replication through multiple mechanisms. Nature 411: 1068-1073.

Nordman J, Li S, Eng T, Macalpine D, Orr-Weaver TL. 2011. Developmental control of the DNA replication and transcription programs. Genome Res 21: 175-181.

Nordman JT, Kozhevnikova EN, Verrijzer CP, Pindyurin AV, Andreyeva EN, Shloma VV, Zhimulev IF, Orr-Weaver TL. 2014. DNA copy-number control through inhibition of replication fork progression. Cell Rep 9: 841-849. 
Ozeri-Galai E, Bester AC, Kerem B. 2012. The complex basis underlying common fragile site instability in cancer. Trends $\mathrm{Ge}$ net 28: 295-302.

Paeschke K, Capra JA, Zakian VA. 2011. DNA replication through G-quadruplex motifs is promoted by the Saccharomyces cerevisiae Pifl DNA helicase. Cell 145: 678-691.

Petermann E, Orta ML, Issaeva N, Schultz N, Helleday T. 2010. Hydroxyurea-stalled replication forks become progressively inactivated and require two different RAD51-mediated pathways for restart and repair. Mol Cell 37: 492-502.

Pierce AJ, Hu P, Han M, Ellis N, Jasin M. 2001. Ku DNA end-binding protein modulates homologous repair of double-strand breaks in mammalian cells. Genes Dev 15: 3237-3242.

Poli J, Tsaponina O, Crabbe L, Keszthelyi A, Pantesco V, Chabes A, Lengronne A, Pasero P. 2012. dNTP pools determine fork progression and origin usage under replication stress. $E M B O$ J 31: 883-894.

Redon C, Pilch DR, Rogakou EP, Orr AH, Lowndes NF, Bonner WM. 2003. Yeast histone 2A serine 129 is essential for the efficient repair of checkpoint-blind DNA damage. EMBO Rep 4: 678-684.

Rogakou EP, Pilch DR, Orr AH, Ivanova VS, Bonner WM. 1998. DNA double-stranded breaks induce histone $\mathrm{H} 2 \mathrm{AX}$ phosphorylation on serine 139. J Biol Chem 273: 5858-5868.

Saini N, Ramakrishnan S, Elango R, Ayyar S, Zhang Y, Deem A, Ira G, Haber JE, Lobachev KS, Malkova A. 2013. Migrating bubble during break-induced replication drives conservative DNA synthesis. Nature 502: 389-392.

Sakofsky CJ, Ayyar S, Deem AK, Chung WH, Ira G, Malkova A. 2015. Translesion polymerases drive microhomology-mediated break-induced replication leading to complex chromosomal rearrangements. Mol Cell 60: 860-872.

Sanders CM. 2010. Human Pif1 helicase is a G-quadruplex DNAbinding protein with G-quadruplex DNA-unwinding activity. Biochem J 430: 119-128.

Schlacher K, Christ N, Siaud N, Egashira A, Wu H, Jasin M. 2011. Double-strand break repair-independent role for BRCA2 in blocking stalled replication fork degradation by MRE11. Cell 145: 529-542.

Schwab RA, Nieminuszczy J, Shin-ya K, Niedzwiedz W. 2013. FANCJ couples replication past natural fork barriers with maintenance of chromatin structure. I Cell Biol 201: 33-48.

Seo J, Chung YS, Sharma GG, Moon E, Burack WR, Pandita TK, Choi K. 2005. Cdt1 transgenic mice develop lymphoblastic lymphoma in the absence of p53. Oncogene 24: 8176-8186.

Sher N, Bell GW, Li S, Nordman J, Eng T, Eaton ML, Macalpine DM, Orr-Weaver TL. 2012. Developmental control of gene copy number by repression of replication initiation and fork progression. Genome Res 22: 64-75.

Sirbu BM, Couch FB, Feigerle JT, Bhaskara S, Hiebert SW, Cortez D. 2011. Analysis of protein dynamics at active, stalled, and collapsed replication forks. Genes Dev 25: 1320-1327.

Sirbu BM, McDonald WH, Dungrawala H, Badu-Nkansah A, Kavanaugh GM, Chen Y, Tabb DL, Cortez D. 2013. Identification of proteins at active, stalled, and collapsed replication forks using isolation of proteins on nascent DNA (iPOND) coupled with mass spectrometry. I Biol Chem 288: 31458-31467.

Smith AV, Orr-Weaver TL. 1991. The regulation of the cell cycle during Drosophila embryogenesis: the transition to polyteny. Development 112: 997-1008.

Sogo JM, Lopes M, Foiani M. 2002. Fork reversal and ssDNA accumulation at stalled replication forks owing to checkpoint defects. Science 297: 599-602.
Tanaka S, Araki H. 2013. Helicase activation and establishment of replication forks at chromosomal origins of replication. Cold Spring Harb Perspect Biol 5: a010371.

Ticau S, Friedman LJ, Ivica NA, Gelles J, Bell SP. 2015. Singlemolecule studies of origin licensing reveal mechanisms ensuring bidirectional helicase loading. Cell 161: 513-525.

Tomimatsu N, Mukherjee B, Catherine Hardebeck M, Ilcheva M, Vanessa Camacho C, Louise Harris J, Porteus M, Llorente B, Khanna KK, Burma S. 2014. Phosphorylation of EXO1 by CDKs 1 and 2 regulates DNA end resection and repair pathway choice. Nat Commun 5: 3561.

Truong LN, Li Y, Shi LZ, Hwang PY, He J, Wang H, Razavian N, Berns MW, Wu X. 2013. Microhomology-mediated end joining and homologous recombination share the initial end resection step to repair DNA double-strand breaks in mammalian cells. Proc Natl Acad Sci 110: 7720-7725.

Truong LN, Li Y, Sun E, Ang K, Hwang PY, Wu X. 2014. Homologous recombination is a primary pathway to repair DNA double-strand breaks generated during DNA rereplication. I Biol Chem 289: 28910-28923.

Valton AL, Hassan-Zadeh V, Lema I, Boggetto N, Alberti P, Saintome C, Riou JF, Prioleau MN. 2014. G4 motifs affect origin positioning and efficiency in two vertebrate replicators. EMBO J 33: 732-746.

Vasianovich Y, Harrington LA, Makovets S. 2014. Break-induced replication requires DNA damage-induced phosphorylation of Pif1 and leads to telomere lengthening. PLoS Genet 10: e1004679.

Walker JR, Corpina RA, Goldberg J. 2001. Structure of the Ku heterodimer bound to DNA and its implications for doublestrand break repair. Nature 412: 607-614.

Ward IM, Minn K, Jorda KG, Chen J. 2003. Accumulation of checkpoint protein 53BP1 at DNA breaks involves its binding to phosphorylated histone H2AX. I Biol Chem 278: 19579-19582.

Wilson MA, Kwon Y, Xu Y, Chung WH, Chi P, Niu H, Mayle R, Chen X, Malkova A, Sung P, et al. 2013. Pif1 helicase and Pol反 promote recombination-coupled DNA synthesis via bubble migration. Nature 502: 393-396.

Wu Y, Shin-ya K, Brosh RM Jr. 2008. FANCJ helicase defective in Fanconia anemia and breast cancer unwinds G-quadruplex DNA to defend genomic stability. Mol Cell Biol 28: 41164128.

Xouri G, Lygerou Z, Nishitani H, Pachnis V, Nurse P, Taraviras S. 2004. Cdt1 and geminin are down-regulated upon cell cycle exit and are over-expressed in cancer-derived cell lines. Eur $I$ Biochem 271: 3368-3378.

Yan S, Michael WM. 2009. TopBP1 and DNA polymerase- $\alpha$ directly recruit the 9-1-1 complex to stalled DNA replication forks. J Cell Biol 184: 793-804.

Yarosh W, Spradling AC. 2014. Incomplete replication generates somatic DNA alterations within Drosophila polytene salivary gland cells. Genes Dev 28: 1840-1855.

Yoo S, Dynan WS. 1999. Geometry of a complex formed by double strand break repair proteins at a single DNA end: recruitment of DNA-PKcs induces inward translocation of Ku protein. Nucleic Acids Res 27: 4679-4686.

Yu X, Chen J. 2004. DNA damage-induced cell cycle checkpoint control requires CtIP, a phosphorylation-dependent binding partner of BRCA1 C-terminal domains. Mol Cell Biol 24: 9478-9486.

Yu AM, McVey M. 2010. Synthesis-dependent microhomologymediated end joining accounts for multiple types of repair junctions. Nucleic Acids Res 38: 5706-5717. 
Yun MH, Hiom K. 2009. CtIP-BRCA1 modulates the choice of DNA double-strand-break repair pathway throughout the cell cycle. Nature 459: 460-463.

Zellweger R, Dalcher D, Mutreja K, Berti M, Schmid JA, Herrador R, Vindigni A, Lopes M. 2015. Rad51-mediated replication fork reversal is a global response to genotoxic treatments in human cells. J Cell Biol 208: 563-579.

Zhang J, Dewar JM, Budzowska M, Motnenko A, Cohn MA, Walter JC. 2015. DNA interstrand cross-link repair requires replication-fork convergence. Nat Struct Mol Biol 22: 242-247.
Zhu W, Dutta A. 2006. An ATR- and BRCA1-mediated Fanconi anemia pathway is required for activating the G2/M checkpoint and DNA damage repair upon rereplication. Mol Cell Biol 26: 4601-4611.

Zhu W, Chen Y, Dutta A. 2004. Rereplication by depletion of geminin is seen regardless of p53 status and activates a G2/ M checkpoint. Mol Cell Biol 24: 7140-7150.

Zou L, Elledge SJ. 2003. Sensing DNA damage through ATRIP recognition of RPA-ssDNA complexes. Science 300: 15421548. 


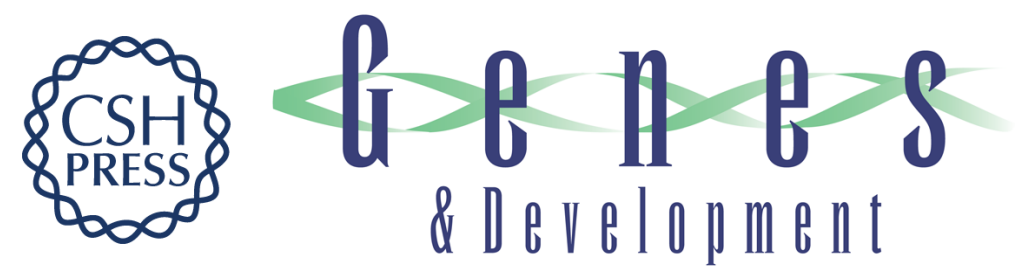

\section{Replication fork instability and the consequences of fork collisions from rereplication}

Jessica L. Alexander and Terry L. Orr-Weaver

Genes Dev. 2016, 30:

Access the most recent version at doi:10.1101/gad.288142.116

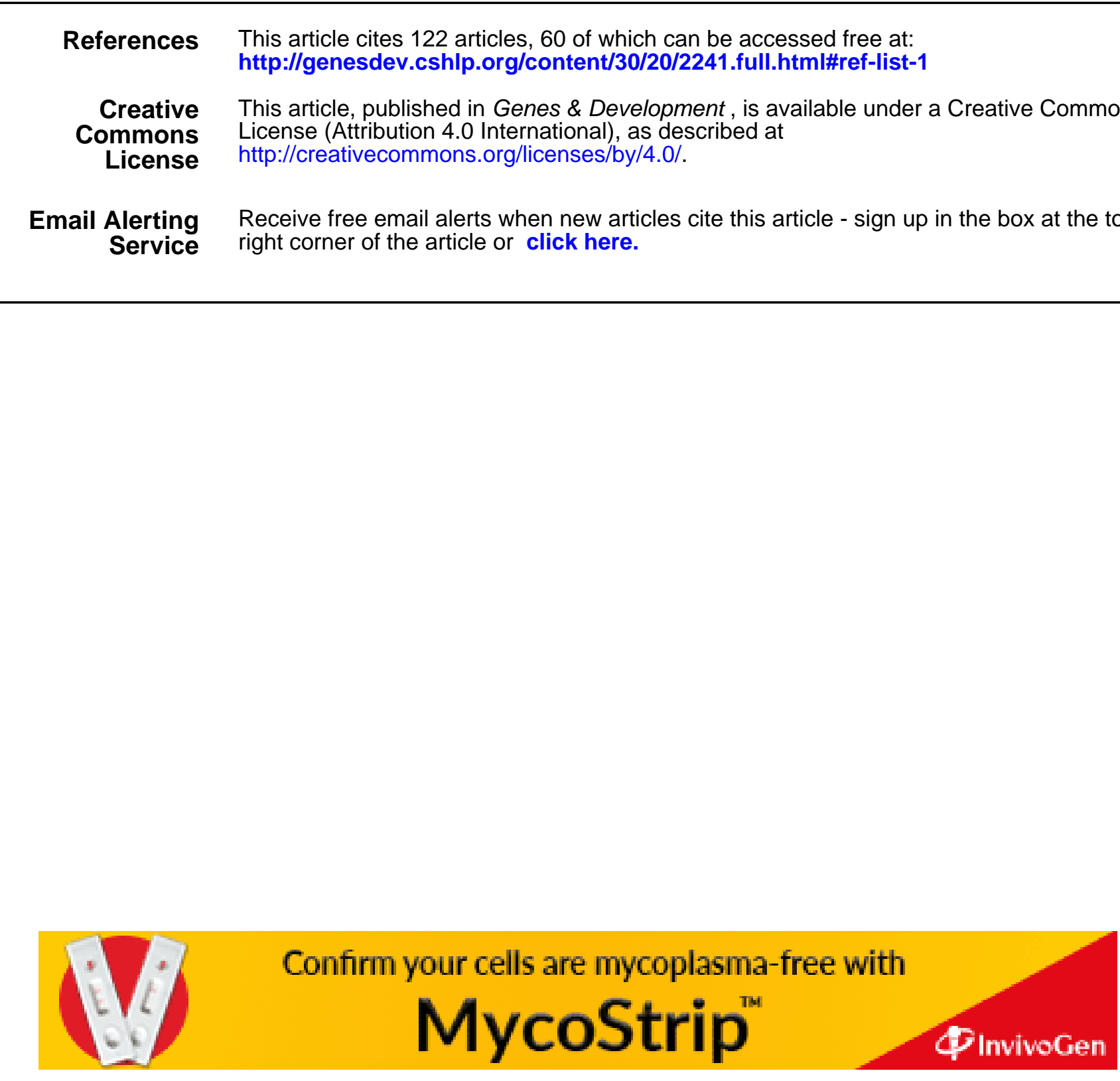

(C) 2016 Alexander and Orr-Weaver; Published by Cold Spring Harbor Laboratory Press 